\title{
Estudos sobre Bombacaceae - II. Anatomia do lenho secundário de Catostemma albuquerquei Paula
}

\author{
José Elias de Paula (*)
}

\section{Resumo}

Continuação de uma série de estudos sobre Bombacaceae. Versa sobre a anatomia da madeira de Catostemma albuquerquei Paula. Esta espécie ocorre em matas da terra firme da região de $\mathrm{Ma}$ naus e municípios limítrofes.

\section{INTRODUÇÃo}

Continuamos neste trabalho a série de estudos das Bombacaceae (Paula, 1969), versando sobre a anatomia do lenho secundário de Catostemma albuquerquei Paula, com vista à Taxonomia e consignar informações concernentes à sua utilização.

\section{MATERIAL E MÉTODOS}

O material que serviu de confirmação da espécie encontra-se depositado nos herbários da Universidade de Brasília (UB) e do Instituto Nacional de Pesquisas da Amazônia, com as indicações seguintes: a) J. Elias de Paula 464 (UB); b) W. Rodrigues et A. Loureiro 7164 (INPA). Os cortes histológicos foram realizados com o micrótomo Jung para madeira, e corados com safranina e verde rápido. Os testes para lignina foram feitos com floroglucina e ácido súlfurico. O oxalato de cálcio foi detectado com ácido sulfúrico a $50 \%$ (Johansen, 1940). A silica foi identificada pela sua solubilidade no ácido fluorídrico, na proporção de $1 \mathrm{ml}$ para $2 \mathrm{ml}$ de água destilada (Molisch. 1923). As fotomicrografias foram obtidas com o Fotomicroscópio Zeiss. Adotamos a terminologia de Metcalfe \& Chalk, 1957; Milanez \& Bastos, 1960; Kribs, 1935; e a recomendada pela Primeira Reunião Sul-Americana de Anatomistas de Madeira, 1936.

\section{Resultados}

Caracteres Gerais - Madeira moderadamente leve; densidade aproximadamente 0,71 ; dureza média; textura média, com tendência à grosseira; grã mais ou menos regular; alburno de cor bege a amarelo-claro; cerne castanho claro, demarcado do alburno; goma-resina de cor bege, um tanto elástica; fácil de se trabaIhar em carpintaria. Casca com superfície lisa, esbranquiçada internamente, em material fres$\mathrm{co}$; espessura entre 1,5 e $2,5 \mathrm{~cm}$; cheiro e sabor indistintos.

Descrição macroscópica (foto 1) - Poros bem distintos a olho nu, por causa do parênquima axial que contorna os mesmos, em geral com goma--resina; distribuição difusa: parênquima axial moderadamente abundante, distinio, em faixas tangenciais, um pouco irregulares, às vezes alado; raios bem visiveis; linhas vasculares visíveis, sempre retas.

Descrição microscópica (fotos 2 a 4) Poros de distribuição difusa, raramente em séries radiais; de secção circular, semicircular

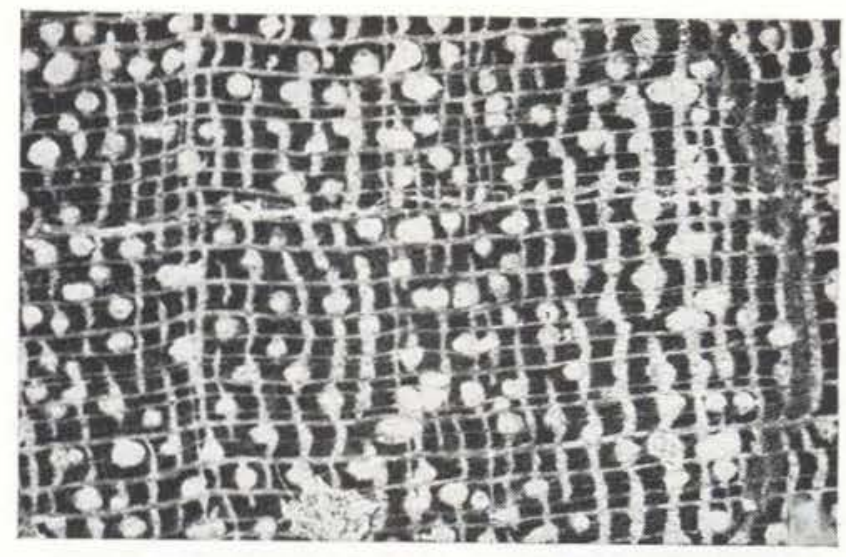

Foto 1 - Aspecto macroscópico (8x)

(*) - Universidade de Brasília - IB 


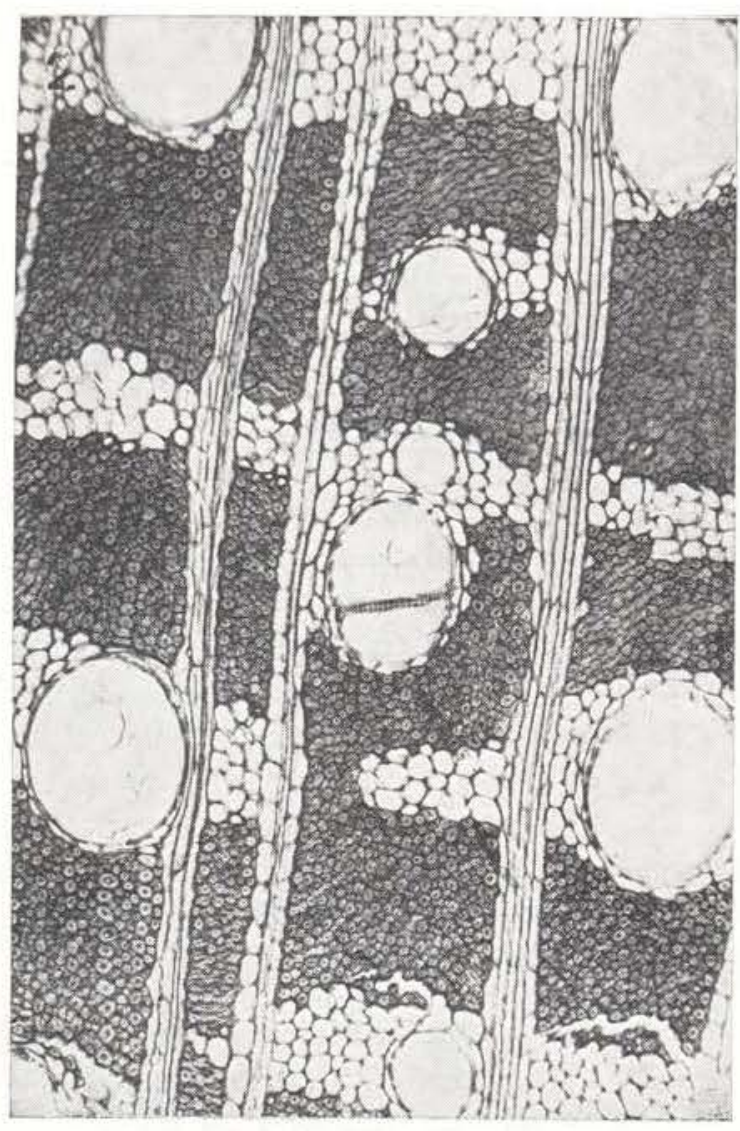

Foto 2 - Secção transversal (100x)

ou oval, predominantemente solitários, raramente geminados e múltiplos de 3 ; grandes, $212 \mu$ de diâmetro tangencial, em média, variando entre 93 e 333 , sendo mais freqüentes entre 204 e 298; são freqüentes poros com ti: los. Elementos vasculares: largos, curtos, 366 $\mu$ de comprimento, em média, variando entre 350 e 388; placa de perfuração simples, total, às vezes orlada; área de perfuração oblíqua Os poros são poucos por $\mathrm{mm}^{2}, 3 \mathrm{em}$ média, variando entre 1 e 4 , sendo $60 \%$ entre 2 e 3 . Pontuações intervasculares: pares areolados, numerosos, de disposição alterna; pontuaçōes de contorno regular, arredondado ou eliptico, com diâmetro entre 5 e $15 \mu$, fenda reduzida, às vezes ampla, inclusa, horizontal. Pontuações parênquimo-vasculares: pares semiareolados, às vezes simplificados (pontuações vasculares perderam progressivamente a arécla), pouco"numerosos, de disposição alterna: pontuações com diâmetro entre 6 e $14 \mu$, fenda estreita ou ampla, inclusa. Pontuações radiovasculares: pares semi-areolados, às vezes simplificados, alternos, numerosos; pontuações de contorno circular, às vezes alongados, inclusas, com diâmetro entre 6 e $16 \mu$, fenda estreita, raramente larga. Raios homogêneos; tipo I de Kribs, 1 a 8 seriados; poucos por mm. 4 em média, variando entre 3 e 6 , sendo mais freqüentes entre 4 e 6 ; baixos, $1,07 \mathrm{~mm}$ de altura, em média, variando entre 0,38 e 2,25 $\mathrm{mm}$, sendo $10 \%$ extremamente baixos $(0,38)$ e $3 \%$ médios $(2,25)$; largos, $170 \mu$ de largura em média, variando entre 35 e 400 , sendo $40 \%$ muito largos (201 a 400) e 10 estreitos (52 a 93 u); com 1 a 92 células em altura, sendo $40 \%$ entre 60 e $79 ; 1$ a 9 células de largura, sendo mais freqüentes entre. 4 e 7 ; os elementos laterais dos raios são mais altos e mais largos do que os mais centrais, tendendo para células envolventes típicas. Raramente ocorrem raios fusionados. São treqüentes células radiais gomíferas. Parênquima axial moderadamente abundante, paratraqueai em faixas, geralmente largas, às vezes aliforme. São freqüentes células desse parên-

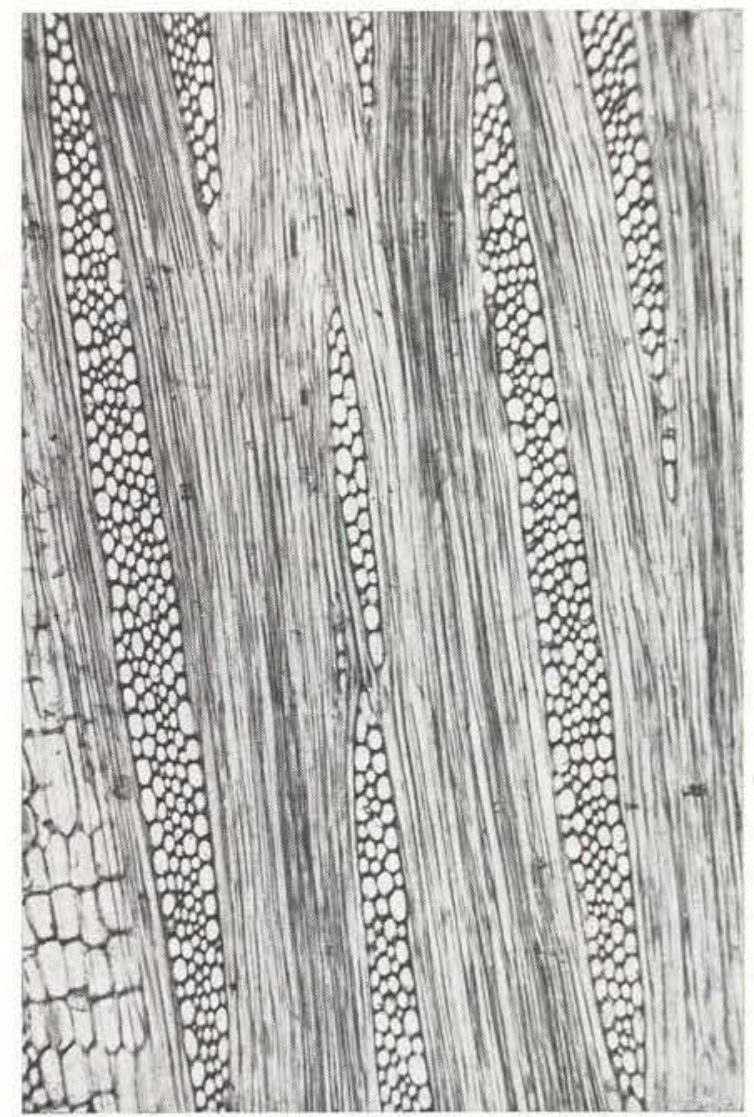

Foto 3 - Secção tangencial (100x) 


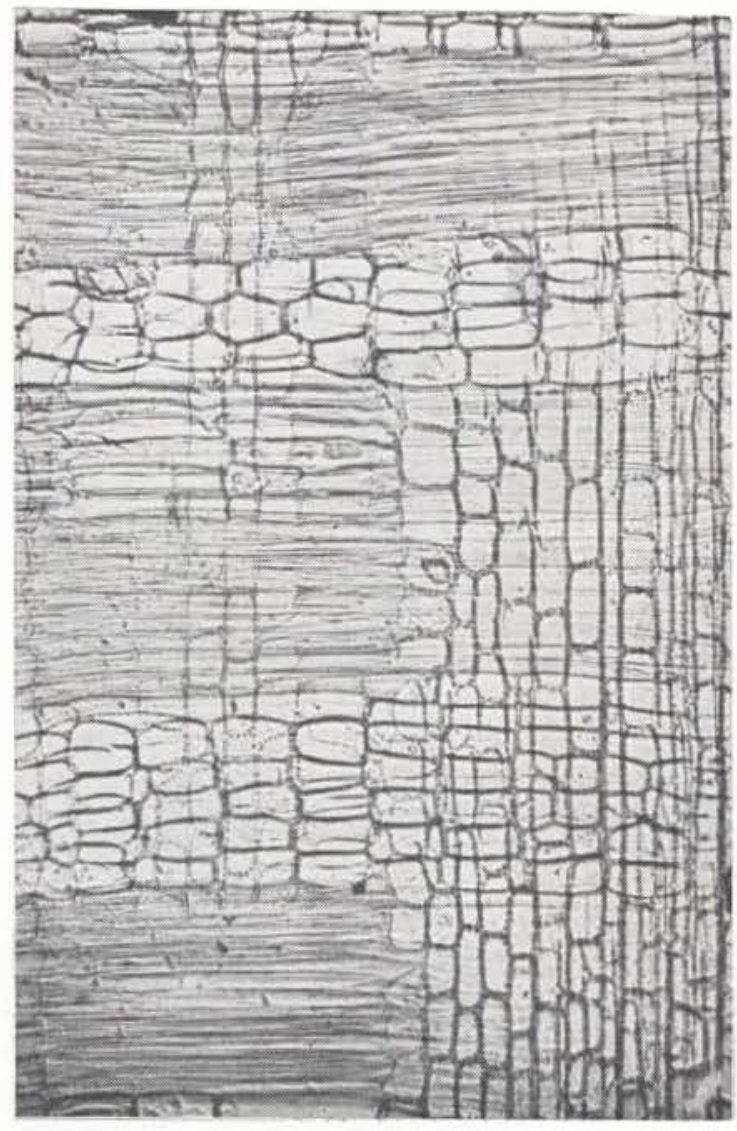

Foto $4-$ Secção radial $(100 x)$

quima com cristais rômbices de oxalato de cálcio e outras com corpos silicosos. Fibras abundantes, em grupos formando "lâminas": elementos fibrosos curtos, $0,65 \mathrm{~mm}$ de comprimento, em média, variando entre 0,35 e 1,06; muito espessos, cujo lúmem corresponde a menos de $1 / 3$ do diâmetro total do elemento; com pontuaçōes simples, muito pequenas. As fibras possuem um teor relativamente baixo de lignina, igualmente as células dos parênquimas radial e axial.

Como já salientamos, a madeira de Catostemma albuquerquei é moderadamente mole, de fibras muite espessas, ricas em celulose $c$ pobre em lignina, cujo comprimento atinge até $1,06 \mathrm{~mm}$. Essas características indicam a viabilidade de um estudo com vista à produçăo de polpa para papel.

\section{SUMMARY}

This paper is the continuation of a series of studies on Bombacaceae. In this contribution we study the wood anatomy of Catostemma albuquerquei Paula of the Amazon region.

\section{BIBLIOGRAFIA CITADA}

JOHANSEN, A. D.

1940 - Plant microtechnique. New York. McGraw-Hill. 523 p., 110 fig.

KRIBS, D. A.

1935 - Salient lines of structural specialization in the wood rays of dicotyledons. Bot. Gaz., USA, 96(3) : 547-557, 7 fig., 1 tab.

Metcalfe, C. R. \& Chalk, K.

1957 - Anatomy of the dicotyledons. Oxford, Clarendon. 2v., v. 1, 724 p., 167 fig.

Milanez, F. R. \& Bastos, A. M.

1960 - Glossário dos têrmos usados em ana. tomia de madeira. Rio de Janeiro, Irmãos \& Cia., ed., 27 p.

MoLisCH, H.

1923 - Mikrochemie der pflanzen. Wien. $438 \mathrm{p}$. 135 fig.

PAULA, J. E. DE

1969 - Estudos sobre Bombacaceae I. Cointribuição para o conhecimento dos gêneros Catostemma Benth, e Scleronema Benth., da Amazônia. Ciência e Cultura, São Paulo, 21(4):697-719, 28 fig.

REUNIĀo SUL-AMERICANA DE ANATOMISTAS DE

MADEIRA, 1.a 1936

1937 - Rodriguésia, Rio de Janeiro, 11:305-384. 